\title{
Assessment of consultation impact on emergency department operations through novel metrics of responsiveness and decision-making efficiency
}

\author{
Patricia A. Lee, BMSc*; Brian H. Rowe, MD, MSc, CCFP(EM), FCCP'; Grant Innes, MD ${ }^{\ddagger}$; \\ Eric Grafstein, $\mathrm{MD}^{\S}$; Renee Vilneff, $\mathrm{BScN}, \mathrm{RN}^{\ddagger}$; Dongmei Wang, $\mathrm{PhD}^{\ddagger}$; Susan van \\ Rheenen, RN, MA, PhD ${ }^{\ddagger}$; Eddy Lang, MD, CCFP(EM), $\mathrm{CSPQ}^{\ddagger}$
}

\section{ABSTRACT}

Objectives: Requests for specialty consultation are common in emergency departments (EDs) and often contribute to delays in throughput. Our objectives were to describe the contribution of the consultation process to total ED length of stay (LOS) through novel metrics and illustrate causes of delay.

Methods: We conducted a prospective cross-sectional study at three Canadian tertiary care centres. Adult ED patients with requested medical/surgical consultations were enrolled. We created original metric intervals: total consultation time (TCT) defined as the interval from the initial consultation request to the disposition decision, consult response time (CRT) from the request to the consultant arrival, and decision-making interval (DMI) from arrival to the disposition decision. The consultation impact index (CII) was defined as the percentage of ED LOS consumed by the TCT. Reasons for delay were documented if time stamps exceeded preset benchmarks.

Results: The median TCT for 285 patients was 138 minutes (interquartile range [IQR]: 82-239 minutes), whereas the median total ED LOS was 778 minutes (IQR 485-1,274 minutes). The median CRT was 55 minutes (IQR 21-115 minutes), and the median DMI was 58 minutes (IOR 25-126 minutes). The Cll measured $26 \%$ (95\% Cl 23-28). Major contributors to consultation delay included urgent ward issues, simultaneous ED consultations, and the need for additional laboratory or radiographic investigations.

Conclusion: The consultation process is highly variable and has an important impact on ED LOS. We describe novel measures related to consultation performance and provide an analysis of what causes delays. These results can be used to seek improvements in the consulting process.

\section{RÉSUMÉ}

Objectifs: Les demandes de consultation de spécialistes dans les services des urgences (SU) sont chose courante, et elles ont souvent pour effet de ralentir le déroulement des interventions. L'étude visait à déterminer la part du processus de consultation dans la durée de séjour (DS) totale au SU à I'aide de nouvelles mesures et à justifier les causes des retards.

Méthode: Il s'agit d'une étude transversale, prospective, qui a été menée dans trois centres hospitaliers de soins tertiaires, au Canada. Ont participé à I'étude des adultes qui sont allés aux SU et pour lesquels des consultations en médecine ou en chirurgie ont été demandées. Nous avons conçu de nouveaux intervalles de mesure: le temps total de consultation (TTC), défini comme le temps écoulé depuis la première demande de consultation jusqu'à la décision relative au sort du malade; le temps de réaction à la demande de consultation (TRC), calculé depuis la demande de consultation jusqu'à l'arrivée du médecin consultant; et l'intervalle de prise de décision (IPD), entendu comme le temps écoulé depuis I'arrivée du malade jusqu'à la décision relative à son sort. L'indice d'incidence des consultations (IIC) a été défini comme le pourcentage de la DS au SU consacré au TTC. Des justifications ont été fournies si les estampilles temporelles révélaient un dépassement des limites préétablies.

Résultats: Le TTC médian, mesuré chez 285 patients s'est élevé à 138 minutes (écart interquartile [EIQ]: 82-239 minutes) et la durée de séjour (DS) totale médiane au SU, à 778 minutes (EIQ: 485-1274 minutes); le TRC médian était de 55 minutes (EIQ: 21-115 minutes) et I'IPD médian, de 58 minutes (EIQ: 25-126 minutes). L'IIC s'est établi à 26\% (IC à 95\%: 23-28). Les principaux facteurs ayant participé aux retards de consultation comprenaient les problèmes urgents

From the *Faculty of Medicine and Dentistry, University of Alberta, Edmonton, AB; †Department of Emergency Medicine and School of Public Health, University of Alberta, Edmonton, AB; $₫ D$ Department of Emergency Medicine, University of Calgary, Calgary, AB; and §Department of Emergency Medicine, University of British Columbia, Vancouver, BC.

Correspondence to: Dr. Eddy Lang, Department of Emergency Medicine, University of Calgary, Calgary, AB T2N 2T9; eddy.lang@albertahealthservices.

This article has been peer reviewed. 
dans les services, les demandes concomitantes de consultation aux SU et la nécessité de demander des examens de laboratoire ou de radiologie complémentaires.

Conclusions: Le processus de consultation varie grandement d'un centre à l'autre et il a une forte incidence sur la DS au SU. Nous avons fait état de nouvelles mesures de la performance des consultations et analysé les causes des retards. Les résultats de l'étude peuvent servir à améliorer le processus de consultation.

Keywords: consultations, metrics, throughput
Consultations with inpatient colleagues are used for approximately one-third of patients seen in highvolume, urban tertiary care emergency departments (EDs) in Canada. ${ }^{1-3}$ In the consultation process, emergency physicians contact specialty services to assist in a patient's care. Requests for consultation are made for different reasons, including hospital admission, treatment or procedure (performed by the consulting service), opinion only, and outpatient referrals. ${ }^{3,4}$

Overcrowding is a crisis for many urban, highvolume EDs in Canada, and a conceptual model compartmentalizes the cause into input, throughput, and output domains. ${ }^{5}$ The consultation process, which is considered part of the throughput phase, can be considered as two sequential intervals: the consultant response time (CRT) and the decision-making interval (DMI). Delays in either can prolong ED length of stay (LOS), and the degree of delay varies by service..$^{6-10}$ Some of the problems identified by emergency physicians include the accessibility and availability of consultants, interactions with consultants, and the disposition decision process. ${ }^{2,3}$ Despite their importance, little is known about the causes of consultation delays and the metrics required to measure them.

Our main objective was to determine the contribution of the consultation process to the total ED LOS through novel measures created for this study. As a secondary objective, we describe causes of consultation delay.

\section{METHODS}

\section{Study design}

This was a prospective, cross-sectional study that examined key time intervals following emergency physician requests for medical, surgical, or social services consultation. This study was approved by the University of Calgary Research Ethics Board (REB). The requirement for patient consent was waived by the REB as this was a quality improvement study involving the collection of accurate time stamps around various aspects of the consultation process, which posed no risk to patients.

\section{Study setting and population}

This study was conducted at the three universityaffiliated tertiary care hospitals in a large Canadian city where consultation is a prerequisite for admission. Patients over the age of 18 with high acuity (Canadian Triage Acuity Scale $1-3)^{11-13}$ who had a medical or surgical services consultation were considered for the study. Patients presenting with a stroke, an acute myocardial infarction, or injuries requiring trauma team activation were excluded from this study as consultations to the corresponding services are prioritized and often initiated directly at triage before physician assessment. Patients who were referred directly to outpatient consultation were also excluded because in-house consultants would not see them within their ED visit. In cases where patient-observed consultation time stamps could not be completed, records were kept, but subjects were not included in data analysis. A summary of those patients can be seen in Table 1.

\section{Study protocol}

Using data from a pilot study of consultation rates during January to December 2009, a convenience sampling of shifts was selected to mirror the percentage of consultations that occurred during daytime (0800-1600h), evening (1600-2400h), and night (0000-0800h) shifts. Potential study participants were identified using an electronic tracking system known as the Regional Emergency Department Information System (REDIS). A serial sampling technique was used to select every second eligible patient from REDIS for the study. Our goal was to study 100 consultation processes at each of the three study sites.

\section{Data collection}

A visual depiction of our new consultation metrics can be seen in Figure 1. Consultation request time was documented from the electronic medical record. 


\begin{tabular}{lcc|}
\hline Table 1. Overview and comparison of patients included and excluded (due to missing time stamps) in the final statistical analysis \\
\hline Characteristic & Included patients $(n=285)$ & Excluded patients ( $n=98)$ \\
\hline Median age (yr) & 56.0 & 53.6 \\
Male sex (\%) & 53.0 & 58.2 \\
CTAS 3 (\%) & 57.5 & 41.8 \\
Arrival time (\%) & 50.2 & 45.9 \\
Day (0800-1559h) & 29.5 & 35.7 \\
Evening (1600-2359h) & 20.3 & 18.4 \\
Night (0000-0759h) & 74.7 & 48.0 \\
Admitted from ED (\%) & $778(485-1,274)$ & $581(350-1,060)$ \\
ED LOS (min) & $943(610)$ & $764(550)$ \\
$\quad$ Median (IQR) & & \\
Mean (SD) & &
\end{tabular}

Consultant arrival and disposition decision time stamps were directly observed and documented by research assistants stationed in the ED. CRT was defined as the interval from the consultation request to consultant arrival, whereas DMI was the interval from consultant arrival to the disposition decision. Total consultation time (TCT) was the sum of these two intervals. When the CRT exceeded 1 hour or the DMI exceeded 2 hours, the consulting staff or residents were asked to describe reasons for the delay using predefined response options.

\section{Outcomes measures}

Our main study outcome was the consultation impact index (CII) metric, defined as the proportion of ED stay attributable to the consultation process (i.e., TCT/ED LOS). Secondary outcomes included describing perceived causes of consultation delay.

\section{Data analysis}

Median values with interquartile ranges (IQRs) were calculated using STATA Statistical Software Release 11.0 (Stata Corporation, College Station, TX).

\section{RESULTS}

Among 409 screened patients, 98 were excluded due to incomplete data and 311 were analyzed (Figure 2). Of these, $53 \%$ were male and the median age was 55 years (IQR 39-74 years), patient characteristics shown in Table 1. Of 285 patients with completed time stamp data, the median TCT was 138 minutes (IQR 82-239 minutes). The total median ED LOS was 778 minutes (IQR 485-1,274 minutes) for patients for whom a consultation was requested. The median CRT was 55 minutes (IQR 21-115 minutes), whereas the median DMI was 58 minutes (IQR 25-126 minutes). The median CRT and DMI values for the top five most frequently consulted services are shown in Table 2. The calculated CII using mean values of TCT and ED LOS was 26\% (95\% CI 23-28). Table 3 shows our main outcome measures stratified by hospital. Overall, $218(69 \%)$ patients exceeded either a 1-hour CRT $(64 \%)$ or a 2 -hour DMI (36\%) benchmark; 17\% exceeded both. Seventy-five percent of patients requiring an ED consultation were admitted to hospital. Table 3 gives a general overview of all patients with and without requested consultations seen at the three EDs during our sampling period.

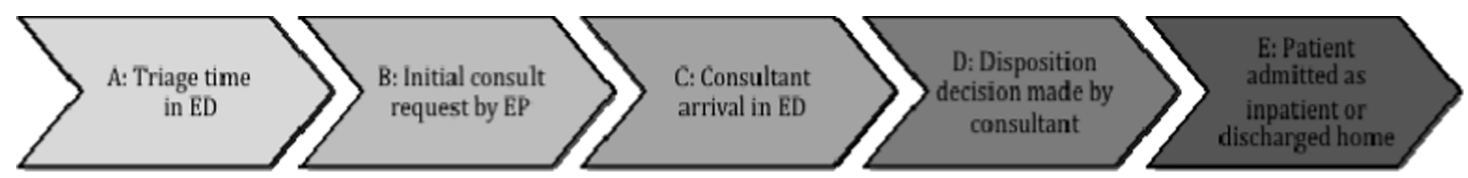

Figure 1. Schematic representation of newly designed consultation measures. A to E: total emergency department (ED) length of stay; B to C: consultant response time; C to D: decision-making interval; $B$ to $D$ : total consultation time. EP = emergency physician. 


\section{Emergency department patient \\ $>18$ years, CTAS $1-3$}

Medical or surgical consultation

request

(Random sampling)

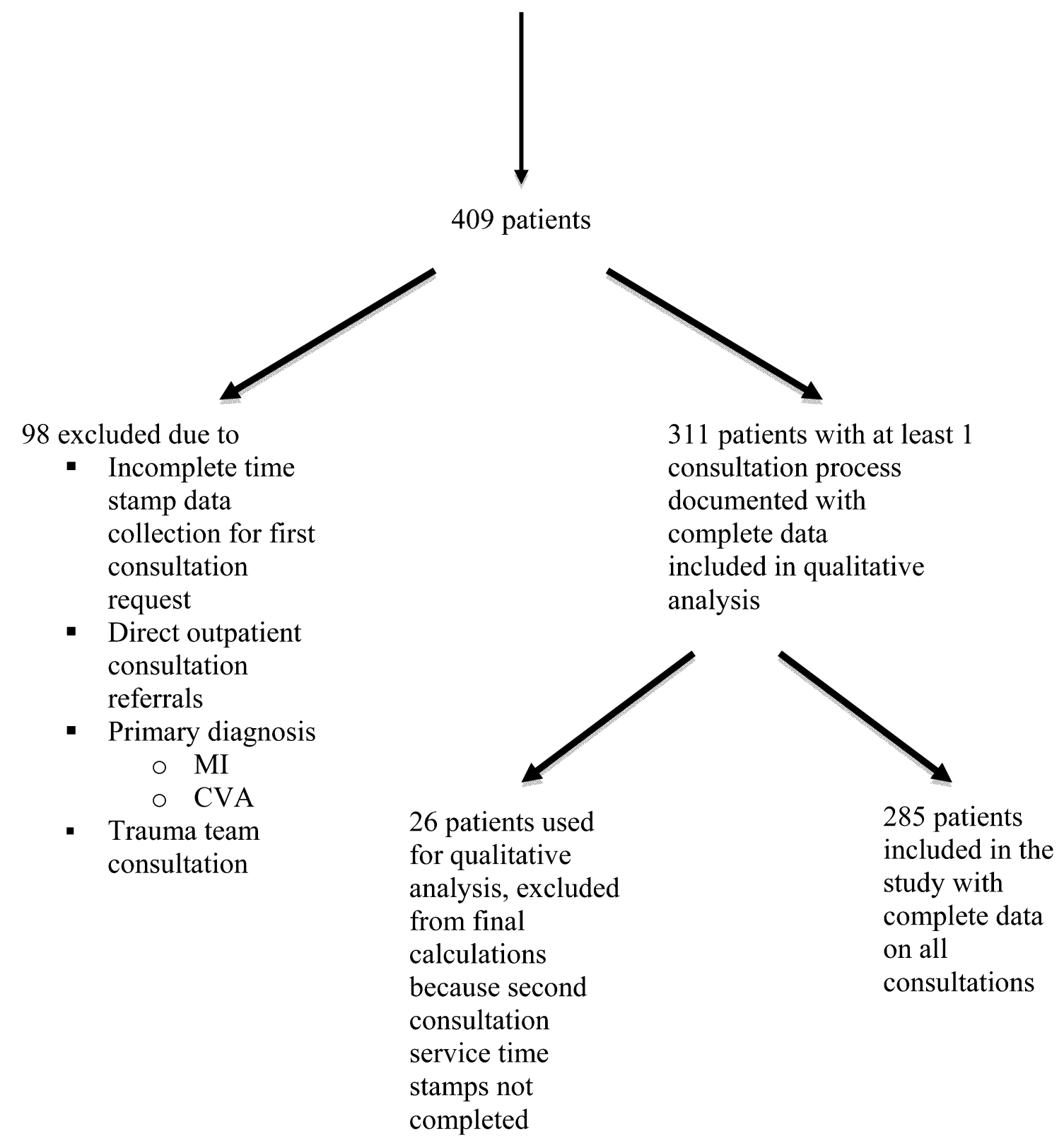

Figure 2. Patient selection process. CTAS = Canadian Triage and Acuity Scale; CVA = cerebrovascular accident; MI = myocardial infarction.

Common reasons for consultation process delays included urgent ward issues (23\%), multiple ED consultations $(22 \%)$, and delays attributed to additional laboratory or radiographic investigations $(17 \%)$ (Figure 3). Twenty-three percent of delays were classified as "other." Some examples of other delays included missing collateral information, complex patients, desired investigation unavailable, and consultants waiting for new staff turnover. Junior team members needed to wait for senior consultant decisions 


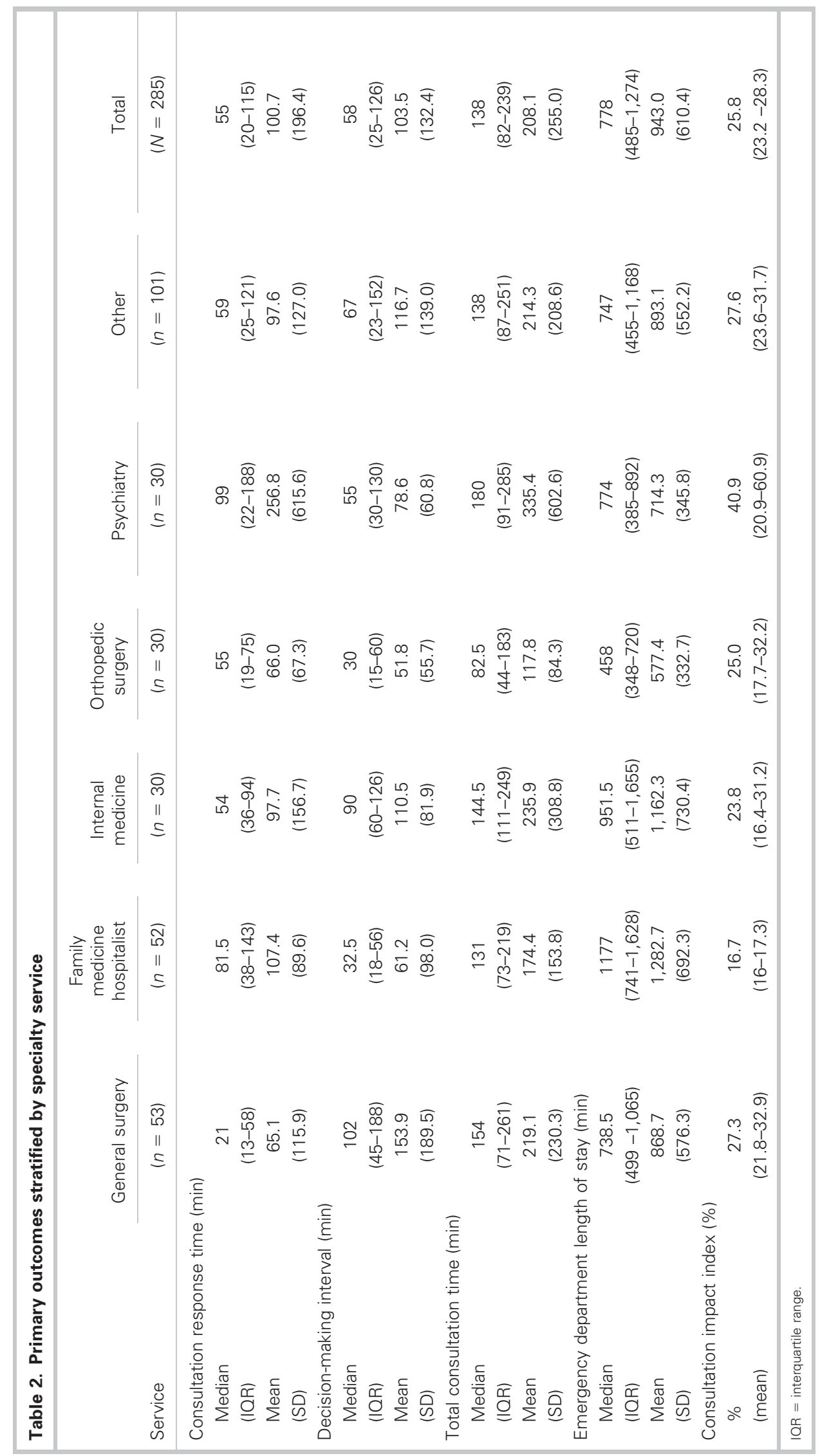




\begin{tabular}{|c|c|c|}
\hline & Patients with consultation & Patients without consultation \\
\hline Characteristic & $(n=8,809)$ & $(n=29,023)$ \\
\hline Age (yr) & 56.6 & 42.4 \\
\hline Male sex (\%) & 50.7 & 48.9 \\
\hline CTAS 1 (\%) & 1.8 & 0.6 \\
\hline CTAS 2 (\%) & 44.0 & 22.5 \\
\hline CTAS $3(\%)$ & 48.2 & 54.9 \\
\hline Admitted from ED (\%) & 64.2 & 5.6 \\
\hline Median ED LOS (h) & 11.3 & 4.1 \\
\hline Median ED LOS (min) & 679 & 246 \\
\hline
\end{tabular}

in $9 \%$ of cases, and $7 \%$ of delays were due to an unavailable service.

\section{DISCUSSION}

This unique North American study describes novel measures that quantify the contribution of the consultation process to total ED LOS. Our CII of $26 \%$ (95\% CI 23-28) reinforces how specialty consultations can be a factor in ED overcrowding and lengthen ED LOS. The results highlight the variability of ED consultations, as shown by the large IQRs in our data set that describes both response times and disposition DMI. There is further variability among different services that may be inherent in their specialty-specific assessment processes. For example, psychiatry has longer consultation times than orthopedics; however, the duration of their requisite evaluations cannot be compared equally. These differences may need to be

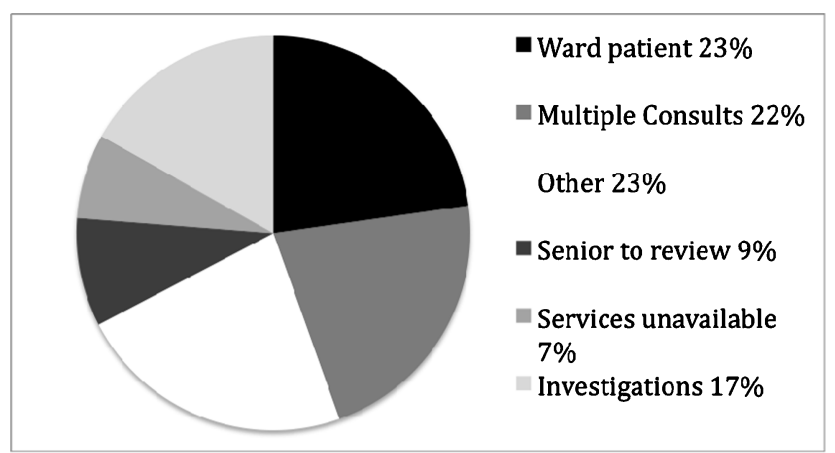

Figure 3. Causes of delay when the consultation request time was $>1$ hour or the decision-making interval was $>2$ hours. taken into account in the creation of institutional benchmarks for consultation services.

Our study shows that consultants perceive the majority of delays as a result of an overwhelmed service that is reported to be busy with ward patients or weighed down by multiple consultations. There is growing research on interventions to reduce specialty consultation times in the ED that address certain contributors of delay identified in our study. A recent Canadian study found that the addition of an acute care emergency surgical services consultation team reduced surgical decision time by $15 \%$ for consulted patients and reduced the time to stretcher for all ED patients by $18 \% .{ }^{14}$ The implementation of a mandated policy on consultation delays led to a threefold reduction in median consultation times in one American centre. ${ }^{15}$ In this study, their intervention included an algorithm with strict guidelines for response times and an ascending scale of informing superiors with plans to respond immediately in case of deviations. In Korea, a computerized consultation system that sent text pages to all residents and staff of a particular service if time to disposition exceeded certain benchmarks reduced both median ED LOS and median time to disposition postintervention. ${ }^{16}$ These studies represent potential solutions that warrant consideration in overcrowded EDs with high volumes of consultations.

The role of emergency physicians in the consultation process requires some consideration. Recent literature describes variability in emergency physician consultation practices but does not examine the appropriateness of these consultation requests; however, Yoon and colleagues demonstrated a significant agreement on admit/discharge decisions $(\kappa=0.77)$ 
between emergency physicians and consultants, ${ }^{6}$ providing indirect evidence that the ED consultation requests may be appropriate. In our study, $75 \%$ of patients with consultation requests were admitted to hospital. The time to consultation decision varies widely across specialties, and it might be informative to examine this decision-making process in more granular detail, teasing out whether the delays are unique to each specialty. It will be imperative to monitor this aspect of ED throughput if collaborative changes initiated with consultant colleagues can improve the processes of care in a mutually beneficial manner.

\section{LIMITATIONS}

This study has several important limitations. First, we chose a limited convenience sample to enable the collection of more detailed data that could not be obtained from an electronic tracking system such as REDIS; hence, our study may have some issues with precision and generalizability. Second, the study was performed in one 3-month period in the summer of 2010 and seasonal variation was not explored. Third, we could not follow consultations that exceeded an 8hour shift for a member of the research team. The majority of these patients were initially enrolled; however, the major time stamps of consultant arrival or disposition decision were not observed by the research assistants and thus were not included for analysis. It is likely that these patients were enrolled in the later part of a sampling shift. Table 1 tells us that the two groups were reasonably comparable, but the patients who missed the study sampling frame did have a modestly reduced consultation burden. It suggests that there may be a modest risk of bias by focusing on patients in whom the burden of consultation is higher than average. Fourth, there was some variability in recording time stamps; the unit clerks who input consultation request times were not informed of the study, and the research team sometimes found it difficult to estimate an exact time of disposition decision with the consultants. Fifth, it is possible that consultant responses may have been biased from the knowledge that our research team was studying their actions. Sixth, this study was conducted in a single centre in Canada, where a universal health care system exists. Consequently, the study may not be generalized to other Canadian and non-Canadian centres. Finally, the CII must be reported and interpreted in conjunction with boarding time and time to emergency physician assessment. Although these factors do not affect the TCT, they do prolong total ED LOS, which represents the denominator in the CII.

\section{CONCLUSIONS}

The consultation process is highly variable and makes an important contribution to total ED LOS. We describe novel measures related to consultation performance and provide an analysis of what causes delays. These results can be used to provide constructive feedback to consulting services and for the development of institutional benchmarks in the hope of significantly addressing ED overcrowding, where the CII is long.

Competing interests: Patricia Lee was funded by the University of Calgary Department of Emergency Medicine as a summer student. This study received no other financial support. Dr. Rowe is supported by the Canadian Institutes of Health Research (CIHR) and the Government of Canada as a 21st Century Canada Research Chair in Emergency Medicine.

\section{REFERENCES}

1. Rosen P. Emergency department disposition and knowledge of other specialties. 7 Emerg Med 1986;4:325-6, doi:10.1016/ 0736-4679(86)90011-9.

2. Woods RA, Lee R, Ospina MR, et al. Consultation outcomes in the emergency department: exploring rates and complexity. CFEM 2008;10:25-31.

3. Lee RS, Woods R, Bullard MJ, et al. Consultations in the emergency department: a systematic review of the literature. Emerg Med 7 2008;25:4-9, doi:10.1136/emj.2007.051631.

4. Guertler AT, Cortazzo JM, Rice MM. Referral and consultation in emergency medicine practice. Acad Emerg Med 1994;1: 565-71, doi:10.1111/j.1553-2712.1994.tb02557.x.

5. Asplin BR, Majid DJ, Rhodes KV, et al. A conceptual model of emergency department overcrowding. Ann Emerg Med 2003;42:181-4, doi:10.1067/mem.2003.302.

6. Yoon P, Steiner I, Reinhardt G. Analysis of factors influencing length of stay in the emergency department. CFEM 2003;5:155-61.

7. Nelson KA, Boslaugh SE, Hodge D 3rd. Risk factors for extremely long length-of-stay among pediatric emergency patients. CFEM 2003;5:155-61.

8. Schull MJ, Slaughter PM, Redelmeier DA. Urban emergency department overcrowding: defining the problem and eliminating misconceptions. CFEM 2002;4:76-83.

9. Drummond AJ. No room at the inn: overcrowding in Ontario's emergency departments. C7EM 2002;4:91-7.

10. Derlet RW, Richards JR. Overcrowding in the nation's emergency departments: complex causes and disturbing 
effects. Ann Emerg Med 2000;35:63-8, doi:10.1016/S01960644(00)70105-3.

11. Beveridge R, Clarke B, Janes L, et al. Canadian Emergency Department Triage and Acuity Scale: implementation guidelines. CFEM 1999;1(3 Suppl):S2-28.

12. Murray M, Bullard M, Grafstein E, CTAS National Working Group; CEDIS National Working Group. Revisions to the Canadian Emergency Department Triage and Acuity Scale implementation guidelines. CFEM 2004;6: 421-7.

13. Bullard MJ, Unger B, Spence J, Grafstein E; CTAS National Working Group. Revisions to the Canadian Emergency Department Triage and Acuity Scale (CTAS) adult guidelines [published erratum appears in CFEM 2008;10:330]. CFEM 2008;10:136-51.

14. Qureshi A, Smith A, Wright F, et al. The impact of an acute care emergency surgical service on timely surgical decisionmaking and emergency department overcrowding. 7 Am Coll Surg 2011;213:284-93, doi:10.1016/j.jamcollsurg.2011.04.020.

15. Brenner BE, Holmes TM, Simpson DD, et al. Reducing specialty consultation times in the emergency department. Acad Emerg Med 2004;11:463, doi:10.1197/j.aem.2004.02.244.

16. Cho SJ, Jeong J, Han S, et al. Decreased emergency department length of stay by application of a computerized consultation management system. Acad Emerg Med 2011;18: 398-402, doi:10.1111/j.1553-2712.2011.01039.x. 